\title{
Ceramic Coatings for Pigments
}

\author{
A.R. Mirhabibi \\ ${ }^{1}$ Institute for Materials Research (IMR), Leeds University, \\ ${ }^{2}$ Center of Excellence for Advanced Materials and Processes (IUST) \\ ${ }^{3}$ Iran University of Science and Technology (IUST) \\ 1 1UK \\ 2,3 Iran
}

\section{Introduction}

Special effect pigments, which can be natural or synthetic, show outstanding qualities of luster, brilliance and iridescent colour effects based upon optically thin layers [1.1-1.4]. This visual impression develops by reflection and scattering of light on thin multiple layers. In nature this is not limited to pearls and mussel shells alone; there are a multitude of birds, fish, precious stones and minerals, even insects, that demonstrate a luster effect. Experiments to understand the optical principles of natural pearl luster demonstrate that the brilliant colours are based upon structured biopolymers and upon layered structures, which are developed by biomineralization. Figure 1.1 illustrates the various optical principles of conventional pigments (A) (absorption pigments), metal effect pigments (B), and pearls (C) and pearl luster pigments (D), the most important group of special effect pigments. In the case of absorption pigments, the interaction with light is based upon absorption and/or diffuse scattering. A completely different optical behavior can be observed with the group of effect pigments including pearl luster and metal effect pigments. Metal effect pigments consist of small metal platelets (for example aluminum, titanium, copper), which operate like little mirrors and almost completely reflect the incident light.

Pearl luster pigments simulate the luster of natural pearls. They consist of alternating transparent layers with differing refractive indices. The layers consist of $\mathrm{CaCO}_{3}$ (high refractive index) and proteins (low refractive index). This difference in refractive indices, arising equally on the interface between an air/oil film or oil film/water, is a prerequisite for the well-known iridescent colour images in these media. Small highly refractive platelets of pearl luster pigments align themselves parallel in optically thin systems such as paints, printing inks, or plastics. Interference effects develop when the distances of the various layers or the thicknesses of the platelets have the right values. Synthetic pearl luster pigments are either transparent or light-absorbing platelet shaped crystals. They can be monocrystalline, as in $\mathrm{Pb}(\mathrm{OH})_{2} .2 \mathrm{PbCO}_{3}$ and $\mathrm{BiOCl}$, or possess a multi-layered structure in which the layers have differing refractive indices and light absorption properties. The use of pearls and nacreous shells for decorative purposes goes back to ancient times (e.g., in Chinese wood intarsia). The history of pearl pigments dates back to 1656, when French rosary maker Jaquin isolated a silky lustrous suspension from fish scales (pearl essence) and applied this to small beads to create artificial pearls. 
(A)

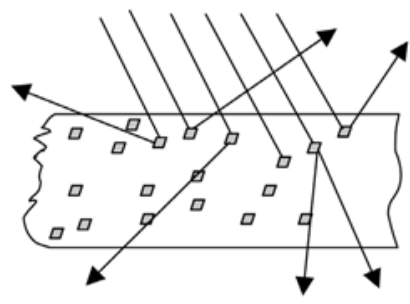

(C)

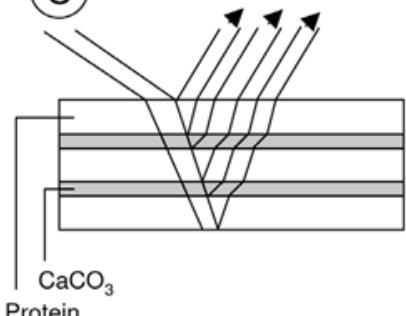

(B)

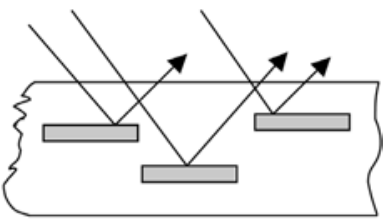

(D)

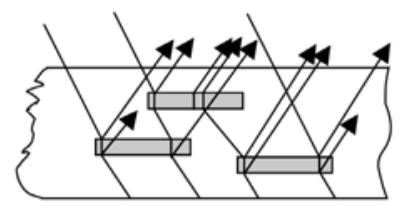

A) conventional pigment; B) metal effect pigment; C) natural pearl; D) pearl luster pigment (1.12).

Fig. 1.1. Optical properties of absorption pigments, effect pigments and natural pearls.

It took more than 250 years to isolate the pearl essence material (guanine platelets) and understand the pearl effect. Attempts were made to create synthetic pearl colours as organic or inorganic, transparent, highly refractive coatings and pearl pigments as crystalline platelets. From 1920 onwards, hydroxides, halides, phosphates, carbonates, and arsenates of zinc, calcium, barium, mercury, bismuth, lead, and other cations were produced for this purpose. Only the traditional natural pearl essence, basic lead carbonate and bismuth oxychloride, is still of importance. The strong demand for pearl effects came from the growing coatings and plastics industries, which wanted to improve the acceptance and popularity of their products. Furthermore, pearl luster pigments also allowed artists and designers to create new visual effects similar to those found in nature. The breakthrough for pearl luster pigments came with the invention of mica coated with metal oxides. Mica-based pearl luster pigments now account for $>90 \%$ of the world market. Important manufacturers of pearl luster pigments are Merck KGaA, Germany (with overseas subsidiaries EMD Chemicals Inc., USA and Merck Ltd., Japan) and Engelhard Corp., USA.

Table 1.1 shows an overview of inorganic pigments with luster effects. Effect pigments can be classified with regard to their composition as metal platelets, oxide-coated metal platelets, oxide-coated mica platelets, oxide-coated silica, alumina and borosilicate flakes, platelet-like monocrystals, comminuted PVD films (PVD = physical vapor deposition), and liquid crystal polymer platelets (LCP-pigments, the only industrially relevant organic effect pigment type) [1.3-1.5]. The aims of new developments are new effects and colours, improvement of hiding power, more intense interference colours, increased light and weather stability, and improved dispersibility. 
Of special interest are pigments which are toxicologically safe and which can be produced by ecologically acceptable processes. The total market for effect pigments can be estimated to be about 50,000 tons per year. Half of this amount can be calculated to be special effect pigments, the other half to be metal effect pigments.

\subsection{Optical principles of pearl luster and interference pigments}

The physical background of optical interference effects has been the subject of many publications [1.1-1.4, 1.6-1.9]. The optical principles of pearl luster (interference) pigments are shown in Figure 1.2 for a simplified case of nearly normal incidence without multiple reflection and absorption. At the interface $\mathrm{P}_{1}$ between two materials with refractive indices $n_{1}$ and $n_{2}$, part of the beam light $\mathrm{L}_{1}$ is reflected $\left(\mathrm{L}_{1}\right)$ and part is transmitted (i.e., refracted) $\left(\mathrm{L}_{2}\right)$. The intensity ratios depend on $n_{1}$ and $n_{2}$. In a multilayer arrangement, as found in pearl or pearl luster and iridescent materials (Figure 1.1D), each interference produces partial reflection. After penetration through several layers, depending on the size of and difference between $n_{1}$ and $n_{2}$, virtually complete reflection is obtained, provided that the materials are sufficiently transparent.

\begin{tabular}{|c|c|}
\hline Pigment type & Examples \\
\hline Metallic platelets & $\begin{array}{l}\mathrm{Al}, \mathrm{Zn} / \mathrm{Cu}, \mathrm{Cu}, \mathrm{Ni}, \mathrm{Au}, \mathrm{Ag}, \mathrm{Fe} \text { (steel), C } \\
\text { (graphite) }\end{array}$ \\
\hline Oxide-coated metallic platelets & $\begin{array}{l}\text { Surface oxidized Cu-, } \mathrm{Zn} / \mathrm{Cu} \text {-platelets, } \mathrm{Fe}_{2} \mathrm{O}_{3} \\
\text { coated Al- platelets }\end{array}$ \\
\hline Coated mica platelets* & $\begin{array}{l}\text { non-absorbing coating: } \mathrm{TiO}_{2} \text { (rutile), } \mathrm{TiO}_{2} \\
\text { (anatase), } \mathrm{ZrO}_{2}, \mathrm{SnO}_{2}, \mathrm{SiO}_{2} \\
\text { selectively absorbing coating: } \mathrm{FeOOH}, \mathrm{Fe}_{2} \mathrm{O}_{3} \text {, } \\
\mathrm{Cr}_{2} \mathrm{O}_{3}, \mathrm{TiO}_{2-\mathrm{x}}, \mathrm{TiO}_{x} \mathrm{~N}_{y}, \mathrm{CrPO}_{4}, \mathrm{KFe}\left[\mathrm{Fe}(\mathrm{CN})_{6}\right] \\
\text { colorants } \\
\text { totally absorbing coating: } \mathrm{Fe}_{3} \mathrm{O}_{4}, \mathrm{TiO}, \mathrm{TiN} \text {, } \\
\mathrm{FeTiO}_{3}, \mathrm{C}, \mathrm{Ag}, \mathrm{Au}, \mathrm{Fe}, \mathrm{Mo}, \mathrm{Cr}, \mathrm{W}\end{array}$ \\
\hline Platelet-like monocrystals & $\begin{array}{l}\mathrm{BiOCl}, \mathrm{Pb}(\mathrm{OH})_{2} \cdot 2 \mathrm{PbCO}_{3}, \mathrm{a}-\mathrm{Fe}_{2} \mathrm{O}_{3}, \mathrm{a}-\mathrm{Fe}_{2} \mathrm{O}_{3} \times n \\
\mathrm{SiO}_{2}, \\
\mathrm{Al}_{x} \mathrm{Fe}_{2-\mathrm{x}} \mathrm{O}_{3}, \mathrm{MnyFe}_{2-\mathrm{y}} \mathrm{O}_{3}, \mathrm{Al}_{x} \mathrm{Mn}_{\mathrm{y}} \mathrm{Fe}_{2-\mathrm{x}-\mathrm{y}} \mathrm{O}_{3}, \\
\mathrm{Fe}_{3} \mathrm{O}_{4} \text {, reduced mixed phases, } \mathrm{Cu}- \\
\text { phthalocyanine }\end{array}$ \\
\hline Comminuted thin PVD-films & $\begin{array}{l}\mathrm{Al}, \mathrm{Cr} \text { (semitransp.) } / \mathrm{SiO}_{2} / \mathrm{Al} / \mathrm{SiO}_{2} / \mathrm{Cr} \\
\text { (semitransp.) }\end{array}$ \\
\hline
\end{tabular}

*Instead of mica other platelets such as silica, alumina, or borosilicate can be used.

Table 1.1. Overview of inorganic effect pigments (1.12) 


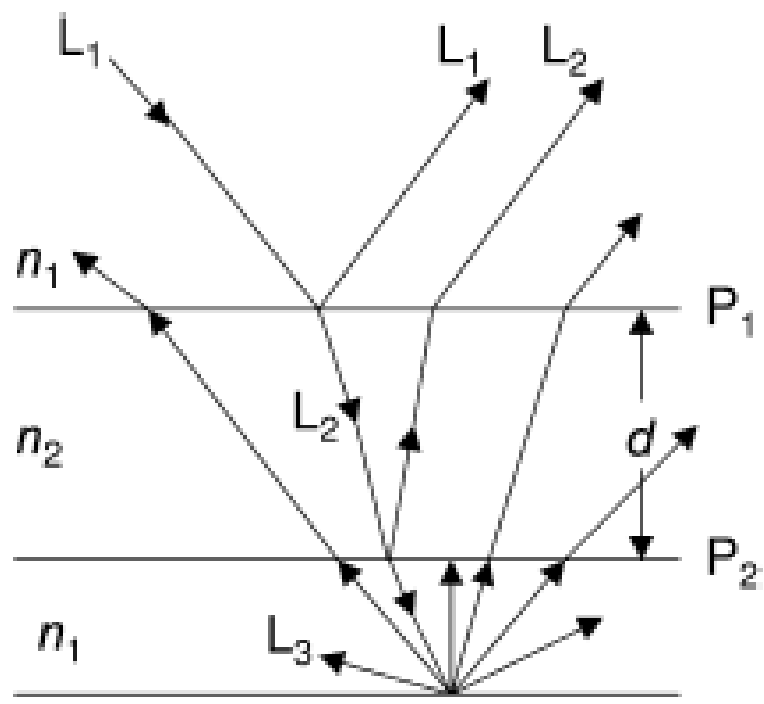

Fig. 1.2. Simplified diagram showing nearly normal incidence of a beam of light $\left(\mathrm{L}_{1}\right)$ from an optical medium with refractive index $n_{1}$ through a thin solid film of thickness $d$ with refractive index $n_{2}$. $\mathrm{L}_{1}$ and $\mathrm{L}_{2}$ are regular reflections from phase boundaries $\mathrm{P} 1$ and $\mathrm{P}_{2}$. $\mathrm{L}_{3}$ represents diffuse scattered reflections from the transmitted light.

In pigments that simulate natural pearl effects, the simplest case is a platelet shaped particle with two phase boundaries $\mathrm{P}_{1}$ and $\mathrm{P}_{2}$ at the upper and lower surfaces of the particles, i.e., a single, thin, transparent layer of a material with a higher refractive index than its surroundings. For small flakes with a thickness of ca. $100 \mathrm{~nm}$, the physical laws of thin, solid, optical films apply.

Multiple reflection of light on a thin solid film with a high refractive index causes interference effects in the reflected light and in the complementary transmitted light. For the simple case of nearly perpendicular incidence, the intensity of the reflectance depends on the refractive indices $\left(n_{1}, n_{2}\right)$, the layer thickness $(\mathrm{d})$, and the wavelength $(\lambda)$ :

$$
\begin{aligned}
& I=\frac{A^{2}+B^{2}+2 A B \cos \Theta}{1+A^{2} B^{2}+2 A B \cos \Theta} \\
& \text { Where } A=\frac{n_{1}-n_{2}}{n_{2}+n_{1}}, B=\frac{n_{2}-n_{1}}{n_{2}+n_{1}}, \Theta=4 \pi \frac{n_{2} d}{\lambda}
\end{aligned}
$$

With given $n_{1}$ and $n_{2}$ the maximum and minimum intensities of the reflected light, seen as interference colours, can be calculated and agree well with experimental results. Values for the refractive indices of the most important materials for pearl luster pigments are shown in Table 1.2. 


\begin{tabular}{|l|c|}
\hline Material & Refractive index \\
\hline Vacuum/Air & 1.0 \\
\hline Water & 1.33 \\
\hline Proteins & 1.4 \\
\hline Organic polymers (plastics, Lacquers, etc.) & $1.4-1.7$ \\
\hline Mica & 1.5 \\
\hline $\mathrm{CaCO}$ (aragonite) & 1.68 \\
\hline Natural pearl (guanine, hypoxanthine) & 1.85 \\
\hline $\mathrm{Pb}(\mathrm{OH})_{2}$. 2PbCO & 2.0 \\
\hline $\mathrm{BiOCl}$ & 2.15 \\
\hline $\mathrm{TiO}_{2}$ (anatase) & 2.5 \\
\hline $\mathrm{TiO}_{2}$ (rutile) & 2.7 \\
\hline $\mathrm{Fe}_{2} \mathrm{O}_{3}$ (hematite) & 2.9 \\
\hline
\end{tabular}

Table 1.2. Refractive indices of materials.

In practice, platelet crystals are synthesized with a layer thickness $d$ calculated to produce the desired interference colours (iridescence). Most pearl luster pigments now consist of at least three layers of two materials with different refractive indices.

Thin flakes (thickness ca. $500 \mathrm{~nm}$ ) of a material with a low refractive index (mica, silica, alumina, glass) are coated with a highly refractive metal oxide $\left(\mathrm{TiO}_{2}, \mathrm{Fe}_{2} \mathrm{O}_{3}\right.$, layer thickness ca. 50-150 nm). This results in particles with four interfaces that constitute a more complicated but still predictable thin film system. The behavior of more complex multilayer pigments containing additional, thin, light-absorbing films can also be calculated if appropriate optical parameters are known.

Colour effects depend on the viewing angle. Pearl luster pigment platelets split white light into two complementary colours that depend on the platelet thickness. The reflected (interference) colour dominates under regular (maximum) reflection, i.e., when the object is observed at the angle of regular reflection. The transmitted part dominates at other viewing angles under diffuse viewing conditions, provided that there is a non-absorbing (white) or reflecting background.

Variation of the viewing angle therefore produces a sharp gloss (reflectance) peak, and the colour changes between two extreme complementary colours. The resulting complex interplay of luster and colour is measured goniophotometrically in reflection and at different angles. A pearl luster pigment is characterized by a minimum of three $L^{*} a^{*} b^{*}$ data sets (CIE $L^{*} a^{*} b^{*}-$ system) measured under different conditions (e.g., $0^{\circ} / 45^{\circ}$ black background, $22.5^{\circ} / 22.5^{\circ}$ black background, $0^{\circ} / 45^{\circ}$ white background). An analysis of these data specifies a pigment on the basis of its hiding power, luster, and hue [1.1, 1.10, 1.11, 1.12].

\section{Application of the Taguchi method to develop a robust design for the synthesis of mica-SnO ${ }_{2}$ gold pearlescent pigment}

\subsection{Introduction}

For a long time beautiful and deep pearlescent pigments have attracted human attention and have been used in many cases [2.1]. These pigments consist of thin transparent small 
flat surfaces with high reflective index. They reflect most of the radiant light and transmit a bit. Simultaneous reflection of light from small parallel surface layers of pigments causes the effect of deepness and brightness, such as exhibited by a pearl [2.2]. Each layer regularly reflects a part of the light and transmits the rest. The transmissible light is again reflected by other layers. Therefore, the manifestation of lustrous and interfering colours are revealed due to reflection from the interface between layers. This phenomenon is observed in natural pearl, fish scale, pearl body, birds feather, the butterfly wing, etc .

Pearlescent pigments are synthesized via two main methods. In the first, single crystals such as $\mathrm{BiOCl}$ or polycrystals like $\mathrm{TiO}_{2}$ are considered as bright and light materials due to their special structure. In the second, the pearlescent state is formed through the coating of materials with a high refractive index, (mainly metal oxide) on a transparent substrate like mica. This group is more important because of higher mechanical stability and brightness [2.3].

One of the most important kinds of these pigments is $\mathrm{TiO}_{2}$ coated mica which due to its high refractive index of $\mathrm{TiO}_{2}$, has high light resistance, low cost, good chemical and heat resistance and nontoxicity has many applications in different industries.

However, a new kind of these pigments is gold pearlescent pigment of mica-tin dioxide which is obtained through coating mica platelets by tin dioxide. This chapter section examines mica-tin dioxide and uses muscovite mica as the substrate and is prepared by laying a particle layer of tin dioxide on its surface. Due to the absorption and reflection of light in this layer, the pigment is termed a colouring pearlescent pigment. This pigment is widely used in many fields such as glass, glaze, automotive, plastics, cosmetics, etc.

The main purpose of this study was to prepare pearlescent pigment and to find the optimum values of process parameters which affect its properties using the Taguchi statistical method.

\subsection{Taguchi techniques}

The Taguchi technique is a powerful tool for the design of high quality systems developed by Taguchi between 1950 to 1960 [2.4-2.6]. It provides a simple, efficient and systematic approach to optimize designs for performance, quality and cost. The methodology is valuable when design parameters are qualitative and discrete. Taguchi parameter design can optimize the performance characteristics through the setting of design parameters and reduce the sensitivity of the system performance to source of variation [2.6-2.7]. This technique is multi-step process, which follow a certain sequence for the experiments to yield an improved understanding of product or process performance. This design of experiments process is made up of three main phases: the planning phase, the conducting phase and analysis interpretation phase. The planning phase is the most important phase and one must give a maximum importance to this phase. The data collected from all the experiments in the set are analysed to determine the effect of various design parameters. This approach is to use a fractional factorial approach and this may be accomplished with the aid of orthogonal arrays. Analysis of variance is a mathematical technique, which is based on a least square approach. The treatment of the experimental results is based on the analysis of average and analysis of variance [2.8-2.9]. 


\subsection{Experimental}

\subsubsection{Raw materials and reagents}

Muscovite mica in bulk state was milled for 1 hour and then sieved and was used as the base. $\mathrm{SnCl}_{2}$ (analytical reagent) was used to produce the metal oxide hydrate on mica flakes and the precipitation was performed by the presence of $\mathrm{KClO}_{3}$ (analytical reagent) as the oxidizing agent. Sorbitan mono-oleate (analytical reagent) was used as the non-ionic surfactant. Also, $\mathrm{NaOH}$ (chemical reagent) and $\mathrm{HCl}$ (chemical reagent) were used for adjustment of $\mathrm{pH}$.

\subsubsection{Design of experiments}

The experiments were conducted by standard orthogonal array. The selection of the orthogonal array is based on the condition that the degrees of freedom for the orthogonal array should be greater than or equal to sum of those lightness and reflective percent parameters [2.6-2.9]. In the present investigation, an L16 orthogonal array was chosen, which has 5 rows and 16 columns as shown in Table 2.1. Table 2.2 indicates the factors and their level. The experiment consists of 16 tests (each row in the L16 orthogonal array) and the columns were assigned with parameters. The first row was $\mathrm{pH}$, second row was reaction temperature (T), third row was concentration of $\mathrm{SnCl}_{2}$ solution $(\mathrm{C})$, fourth row was reaction time $(t)$ and fifth row was stirring rate $(R)$. The response to be studied was the lightness and reflective percent with the objective of the bigger the better. The experiments were conducted by orthogonal array with level of parameters given in each array row. The 1 test results were subject to the analysis of variance.

\begin{tabular}{ccccccccccccccccc}
\hline $\begin{array}{c}\text { Experiment } \\
\text { number }\end{array}$ & 1 & 2 & 3 & 4 & 5 & 6 & 7 & 8 & 9 & 10 & 11 & 12 & 13 & 14 & 15 & 16 \\
\hline $\mathrm{pH}$ & 1 & 1 & 1 & 1 & 2 & 2 & 2 & 2 & 3 & 3 & 3 & 3 & 4 & 4 & 4 & 4 \\
$\mathrm{~T}$ & 1 & 2 & 3 & 4 & 1 & 2 & 3 & 4 & 1 & 2 & 3 & 4 & 1 & 2 & 3 & 4 \\
$\mathrm{C}$ & 1 & 2 & 3 & 4 & 2 & 1 & 4 & 3 & 3 & 4 & 1 & 2 & 4 & 3 & 2 & 1 \\
$\mathrm{t}$ & 1 & 2 & 3 & 4 & 3 & 4 & 1 & 2 & 4 & 3 & 2 & 1 & 2 & 1 & 4 & 3 \\
$\mathrm{R}$ & 1 & 2 & 3 & 4 & 4 & 3 & 2 & 1 & 2 & 1 & 4 & 3 & 3 & 4 & 1 & 2 \\
\hline
\end{tabular}

Table 2.1. Orthogonal array $\mathrm{L}_{16}\left(4^{5}\right)$ of Taguchi [2.4]

\begin{tabular}{ccccc}
\hline \multirow{2}{*}{ Parameters } & \multicolumn{3}{c}{ Levels } \\
\cline { 2 - 5 } $\mathrm{pH}$ & 1 & 2 & 3 & 4 \\
$\mathrm{~T}\left({ }^{\circ} \mathrm{C}\right)$ & 1 & 2 & 2.5 & 3 \\
$\mathrm{C}(\mathrm{g} / \mathrm{lit})$ & 60 & 65 & 70 & 75 \\
$\mathrm{t}(\mathrm{h})$ & 10 & 20 & 40 & 60 \\
$\mathrm{R}($ r.p.m) & 5 & 7 & 8.5 & 10 \\
\hline
\end{tabular}

Table 2.2. Process parameters with their values at four levels 


\subsubsection{Analysis}

The spectral reflectance of the pigment was measured using a Colour Quest Goniospectrophotometer (CE-741-GL-Gretag Macbet Co). The SEM photomicrographs were obtained using an electron microscope (LEO-1455VP) and SEM studies were performed using this microscope equipped with EDX (to determine chemical composition of the observed objects). Appearance and colour of the covered mica flakes were observed by reflectance light microscope (Laborlux 11 pol, Leitz matallux 3). Finally, the phase analysis of the resultant pigment powders was determined by X-ray diffractometer (XRD-PhilipsXpert). Density and particle size of resultant pigment were measured by helium pycnometer (Accupyc 1330) and Master sizer 2000 (Mal 100229) respectively.

\subsubsection{Preparation method}

Firstly, a suitable suspension of $2 \mathrm{~g}$ milled and sieved mica $(20-60 \mu \mathrm{m})$ in $40 \mathrm{ml}$ de-ionized water was prepared. The suspension $\mathrm{pH}$ was adjusted with dilute hydrochloric acid $(5 \%)$ to $\mathrm{pH}$ which is shown in table 2.1 and then heated to desired temperature according to table 2.1 experiment plane. The mixture was heated up to desired temperature, then $0.0001 \%$ (based on mica wt\%) of nonionic surfactant (sorbitan mono-oleate ) was added to this suspension. Then, potassium chlorate aqueous solution $\left(\mathrm{KClO}_{3}\right)$ was added to this suspension as an oxidizing agent.

According to the conditions shown in table 2.1, stirring rate, suspension temperature and $\mathrm{pH}$ were controlled. In order to coat the mica flake, $\mathrm{SnCl}_{2}$ solution and aluminium chloride $\left(\mathrm{AlCl}_{3}\right)$ with a constant proportion $\mathrm{SnCl}_{2} / \mathrm{AlCl}_{3}=9 / 1$, were added to the mica suspension. The $\mathrm{pH}$ of the suspension was kept at desired level by addition of $3 \%$ aqueous sodium hydroxide solution. The coating process was stopped after the desired time. Then, the suspension was filtered and the prepared pigments were washed with distilled water until neutral $\mathrm{pH}$ was reached and dried at $100^{\circ} \mathrm{C}$. Finally the powders were calcined at $950^{\circ} \mathrm{C}$ for $1 \mathrm{~h}$ to get the pigment powders with pearlescent luster.

\subsection{Result and discussion}

\subsubsection{The colour characteristics of pigments}

Lightness $\left(1^{*}\right)$ and reflective percent (R) of pigments were measured using goniospectrophotometer colour analysis apparatus and D65 illuminant in different view angles $\left(20^{\circ}, 45^{\circ}, 75^{\circ}, 110^{\circ}\right)$. The results are shown in table 2.3 .

\begin{tabular}{|c|c|c|c|c|c|c|c|c|}
\hline $\begin{array}{l}\text { Experiment } \\
\text { number }\end{array}$ & 1 & 2 & 3 & 4 & 5 & 6 & 7 & 8 \\
\hline reflection(R)\% & 45 & 75 & 82 & 58 & 46 & 57 & 74 & 79 \\
\hline lightness $\left(1^{*}\right) \%$ & 79.1 & 88.01 & 93.84 & 84.76 & 78.05 & 84.59 & 90.02 & 94.64 \\
\hline $\begin{array}{l}\text { Experiment } \\
\text { number }\end{array}$ & 9 & 10 & 11 & 12 & 13 & 14 & 15 & 16 \\
\hline reflection(R)\% & 82 & 85 & 74 & 54 & 62 & 79 & 59 & 61 \\
\hline lightness $\left(1^{*}\right) \%$ & 93.20 & 95.48 & 88.94 & 83.25 & 84.64 & 90.12 & 82.30 & 83.04 \\
\hline
\end{tabular}

Table 2.3. Results of lightness and reflective percent of pigments 
Doing different analyses such as analysis of variance by using Winrobust software, important parameters were identified. This showed that some of these parameters have less effect in synthesis of the pigments than others. The amount of the effects is shown in figure 2.1.

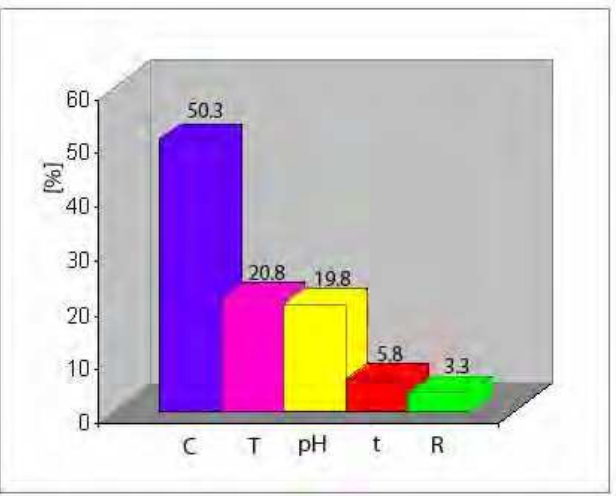

a

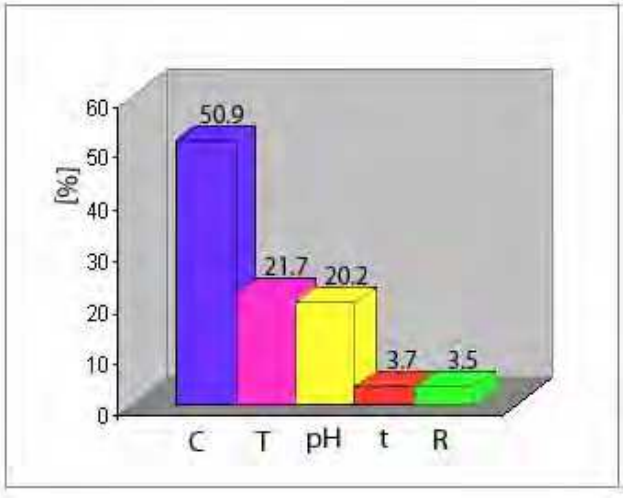

$\mathrm{b}$

Fig. 2.1. Effect of synthesis parameters on the a) lightness and b) reflective percent of pigments

Since in the Taguchi method it is possible that an optimum does not exist in the performed experiments in the designed array [2.10-2.11], some operations were then done by Winrobust software to determine the optimized point. Optimized levels of identified parameters for lightness and reflective percent of pigments is shown in table 2.4.

\begin{tabular}{ccc}
\hline Parameters & Optimize level of lightness & Optimize level of reflection \\
\hline $\mathrm{pH}$ & 3 & 3 \\
$\mathrm{~T}$ & 2 & 2 \\
$\mathrm{C}$ & 3 & 3 \\
$\mathrm{t}$ & 2 & 2 \\
$\mathrm{R}$ & 2 & 2 \\
\hline
\end{tabular}

Table 2.4. Optimized levels of parameters determined with Winrobust software

To confirm this statistical method, synthesis is performed at the optimized conditions. If the experimental results equal the results with Winrobust software, it shows that the method is correct. In figure 2.2, normal probability distribution by Winrobust software is shown for the residual amount in which the continuity of the points in this figure is another confirmation for this method [2.10]. 


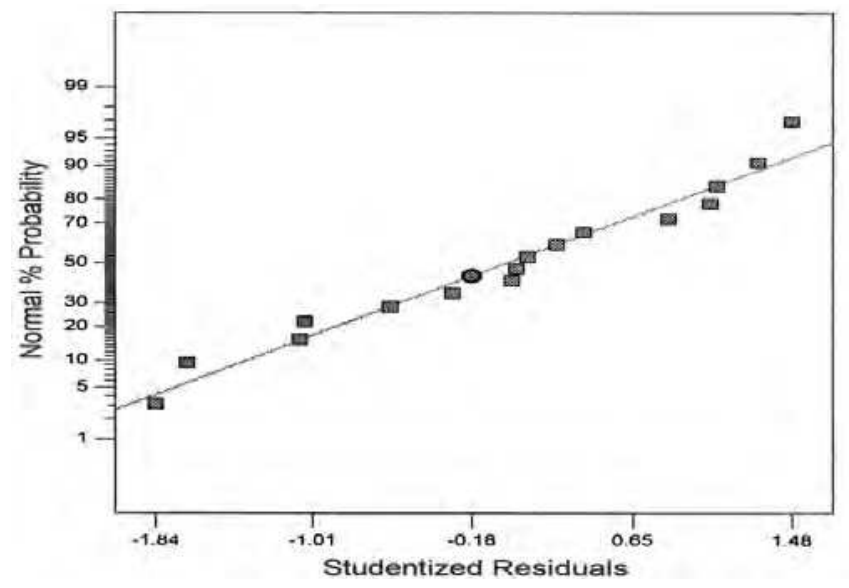

Fig. 2.2. Normal probability distribution of residual amounts

In the following section, according to the presented method and results of experiments, the effect of the parameters has been studied.

\subsubsection{The factors that affect the lightness and reflection of pigment}

\subsubsection{1 pH}

By plotting brightness and reflectance versus $\mathrm{pH}$ based on Taguchi method and using of Winrobust software it can be observed that maximum brightness and reflectance is related to $\mathrm{pH}$ of about level 3 (figure 2.3).

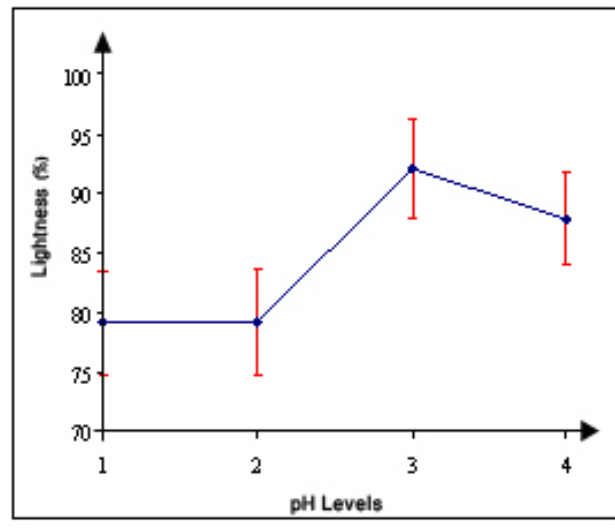

(a)

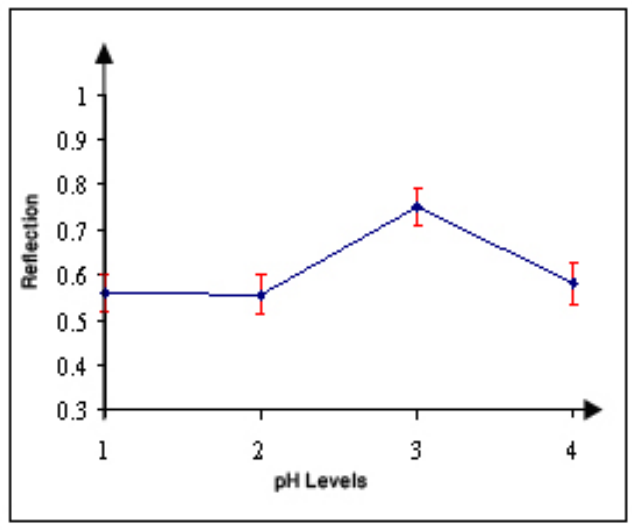

(b)

Fig. 2.3. Effect of parameter $\mathrm{pH}$ on the a) lightness and b) reflection, in different levels

To follow and conform the effect of these changes, SEM and EDS analysis were performed on pigments synthesized at different levels of $\mathrm{pH}$. The results are shown in figures 2.4, 2.5 and 2.6. According to figure 2.4-a, $\mathrm{SnO}_{2}$ particles have precipitated on mica flakes uniformly in sample 9 
which its $\mathrm{pH}$ is optimum ( $\mathrm{pH}=$ level of 3). Figure 4-b (EDS analysis of sample 3) shows a great amount of tin on the mica flakes. In sample 6, only a small quantity of $\mathrm{SnO}_{2}$ particles have been precipitated on mica flakes that its $\mathrm{pH}$ is less than optimum $\mathrm{pH}$ because hydrolysis process has not been performed completely. The results are shown in figures of 2.5-a and 2.5-b but in sample 15 a great amount of $\mathrm{SnO}_{2}$ particles are not agglomerated on the mica flakes uniformly. The results are illustrated in figures 2.6-a and 2.6-b. It seems that due to the progress of hydrolysis the homogeneity of the $\mathrm{SnO}_{2}$ film can vary and the hydrolysis rate is very fast.

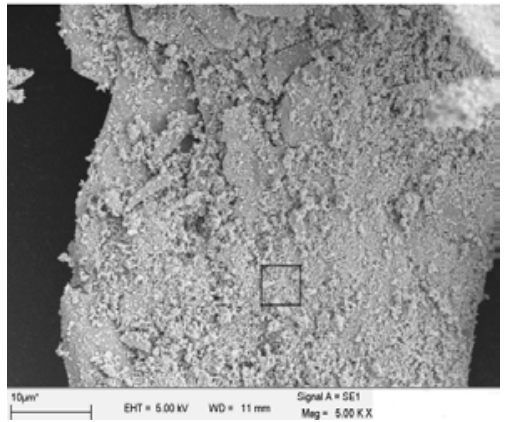

(a)

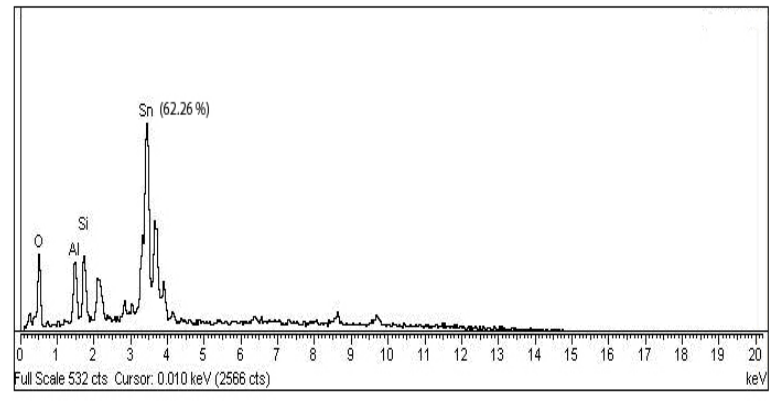

(b)

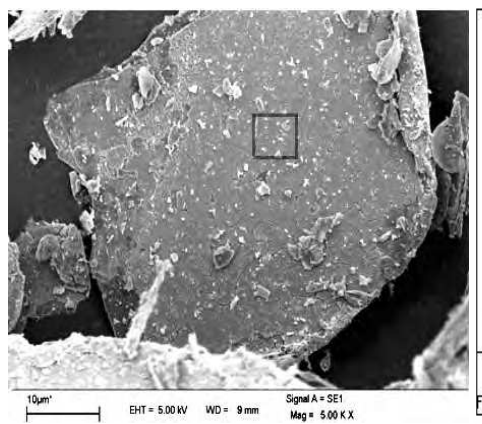

(c)

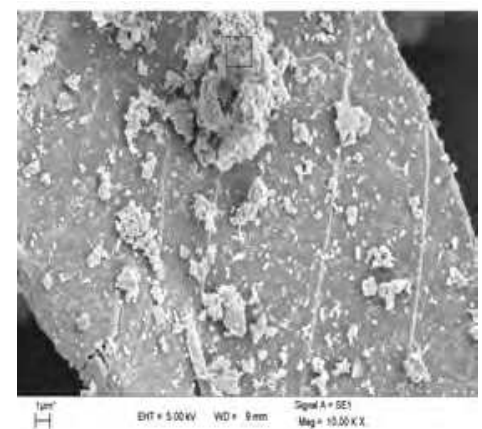

(e)

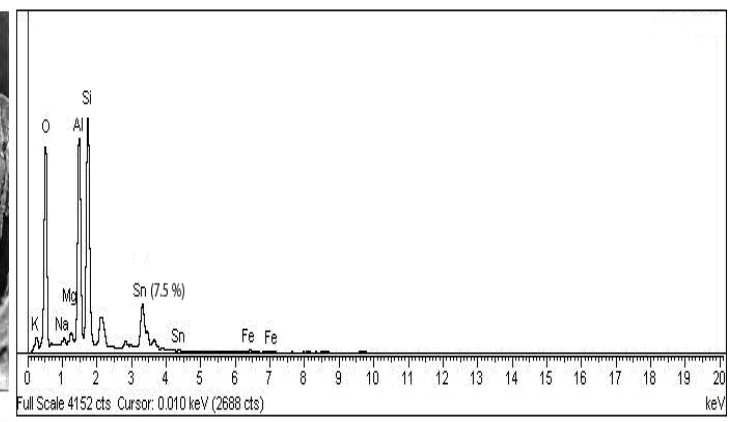

(d)

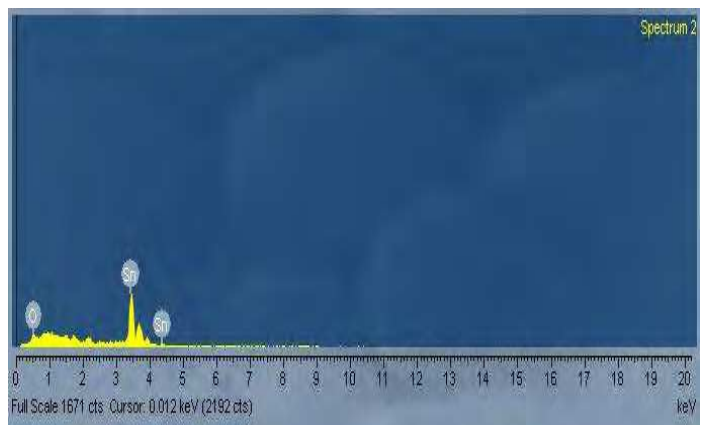

(d)

Fig. 2.4. SEM and EDS Images of pigments synthesized at different levels of $\mathrm{pH}$ 
Therefore, the uniformity of $\mathrm{SnO}_{2}$ coated on mica flakes depends on the hydrolysis rate of $\mathrm{SnCl}_{2}$ solution. The equation of hydrolysis (Equation 1) and rate of hydrolysis (Equation 2) can be considered as follows:

$$
\begin{gathered}
{\left[M\left(\mathrm{OH}_{2}\right)_{N}\right]^{\mathrm{Z}+}+h \mathrm{H}_{2} \mathrm{O} \rightarrow\left[\mathrm{M}(\mathrm{OH})_{h}\left(\mathrm{OH}_{2}\right)_{N-h}\right]^{(\mathrm{Z}-h)^{+}}+h \mathrm{H}^{+}{ }_{\text {Solvated }}} \\
h=\left[\frac{1}{1+0.41 p H}\right]\left[(1.36 \mathrm{Z}-\mathrm{N})(0.236-0.08 p H)-\frac{2.621-0.02 p H-X_{m}^{*}}{\sqrt{X_{m}^{*}}}\right]
\end{gathered}
$$

Where " $\mathrm{h}$ " is the hydrolysis rate, " $\mathrm{Z}$ " is the charge of $\mathrm{M}$ cation, " $\mathrm{N}$ " is the coordination number of $\mathrm{M}, " \mathrm{X}_{\mathrm{m}}^{*}$ " is electronegativity of $\mathrm{M}$. According to the equation (2), if the $\mathrm{pH}$ level is less than the optimum level, the hydrolysis process is not performed and $\mathrm{SnO}_{2}$ particles do not precipitated, because the hydrolysis rate is negative. Therefore, brightness and reflectance will decrease. On the other hand, if the $\mathrm{pH}$ level is more than the optimum level, the hydrolysis rate increases with $\mathrm{pH}$ increasing. Therefore, agglomerated particles are initially formed in suspension and then on the mica flakes. These agglomerated particles cause irregular scattering of light which in turn decrease the brightness and reflectance $[2.12,2.13,2.14]$.

Furthermore, deposition of hydrolysed particles on the mica flakes depends on the electrical charges of hydrolysed particles and mica flakes. On the other hand, the electrical charge of particles in the suspension depends on $\mathrm{pH}$ of the media. Therefore $\mathrm{SnO}_{2}$ particles can precipitate on the mica flakes in a special $\mathrm{pH}$ range. As the electrical charge of mica flakes is negative in the suspension, most of the deposition is performed at a $\mathrm{pH}$ less than 3.5. This is because the charge of $\mathrm{SnO}_{2}$ particles are positive at this $\mathrm{pH}$. The variation of electrical charges can be seen in figure 2.5 .

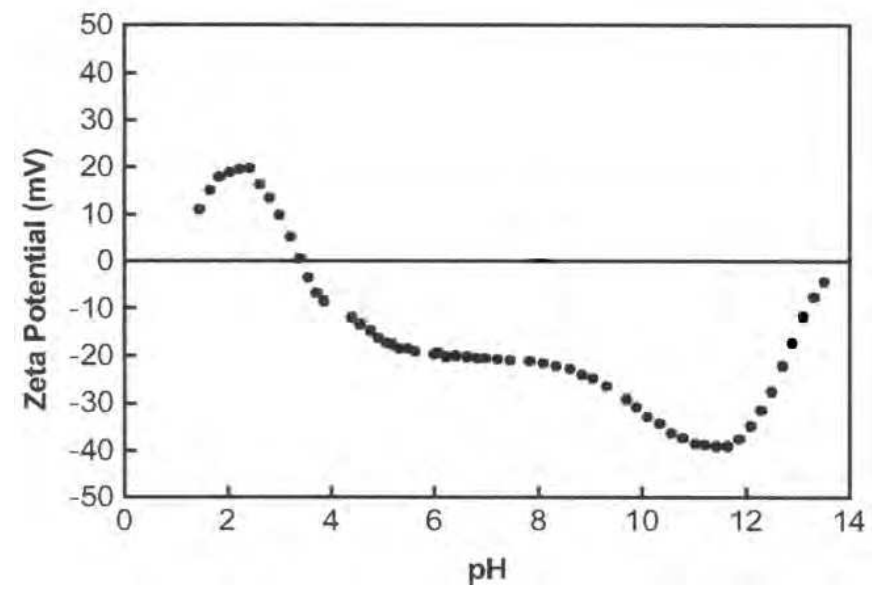

Fig. 2.5. Variation of zeta potential with $\mathrm{pH}$ for $\mathrm{SnO} 2$. Isoelectric point of $\mathrm{SnO}_{2}$ is 3.5 and optimum amount of positive charge of $\mathrm{SnO}_{2}$ particles is $\mathrm{pH} 2.5$ [2.15] 


\subsubsection{Reaction temperature}

By observing brightness and reflectance versus reaction temperature based on Taguchi method and the use of Winrobust software it can be observed that the maximum of brightness and reflectance is related to reaction temperature of about level 2 (figure 2.6).

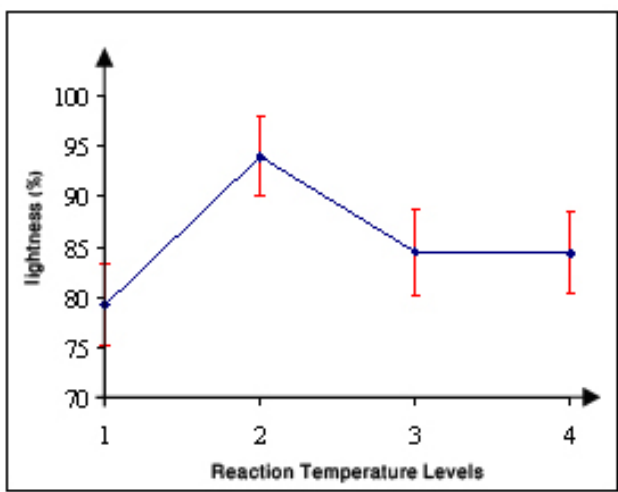

(a)

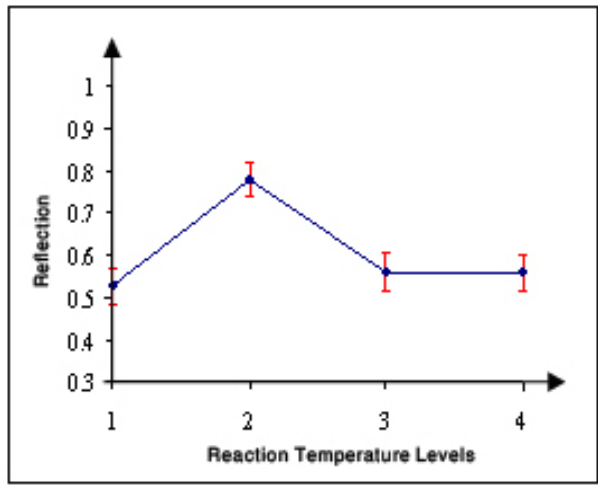

(b)

Fig. 2.6. Effect of parameter temperature on the a) lightness and b) reflection, at different levels

According to SEM analysis observed in figures of 7-a, 7-b and 7-c, when the reaction temperature is low ( $\mathrm{T}=$ level 1$)$, approximately no $\mathrm{SnO} 2$ coating is formed on the mica flakes, thus lightness and reflectance are small (figure 2.7-a). Lightness and reflectance increase with temperature increasing until level of 2 . $\mathrm{SnO}_{2}$ particles coated on the mica flakes are uniform at temperature of level 2 (figure 2.7-b). Increasing temperature causes the flocculation of the colloid particles, the particles become larger, and the membrane on substrate surface becomes loosen and $\mathrm{SnO}_{2}$ particles irregularly deposit on the mica flakes (figure 2.7-c).

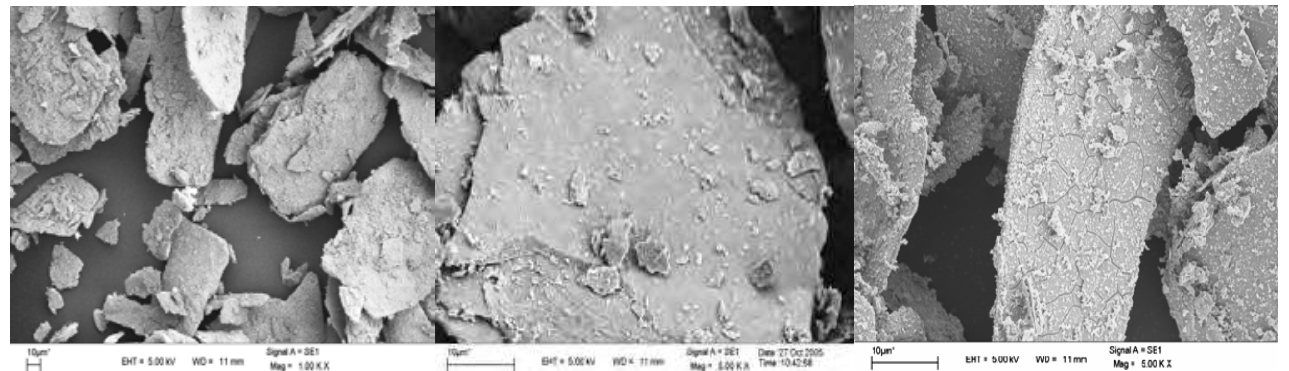

(a)

(b)

(c)

Fig. 2.7. SEM images of pigments synthesized at different levels of reaction temperature

As the hydrolysis process is a precipitation reaction, precipitation decreases with temperature decreasing. This seems to be due to the solubility of tin hydroxide increasing with temperature increasing. So, the precipitate reduces and the coating becomes uneven. 
Also increasing temperature causes the weakening of hydrogen bonding between $\mathrm{SnO}_{2}$ particles and mica flakes [2.13].

\subsubsection{Concentration of $\mathrm{SnCl}_{2}$ solution}

By observing brightness and reflectance versus concentration of $\mathrm{SnCl}_{2}$ solution, based on Taguchi method and the use of Winrobust software it can be observed that the maximum of brightness and reflectance is related to concentration of about level 3 (figure 2.8). It can be seen that with the increase in the concentration of $\mathrm{SnCl}_{2}$ solution, to a level higher than 3 causes the lightness and reflectance of the pigment to decrease.

The relationship between the intensities of reflected light, transmitted light, scattered light, absorbed light and the intensity of incident light is I = S+T+D+A [2.16], where S, T, D and A represent the strength of reflecting light, transmitting light, scattering light and absorbing light respectively. These are function of tin chloride concentration. When I is fixed, the thicker the membrane layer, the larger the value of $\mathrm{A}$, while the smaller the value of $\mathrm{S}$ and $\mathrm{T}$. As $\mathrm{T}$ decreasing, there is less incident light traveling through the coating layer and arriving at the surface of the mica substrate. Thus, the intensity of reflecting light generated at the surface decreases, the reflection and interference action becomes weaker, and the lightness decreases.

Figure 2.9 shows SEM images of a great thickness of $\mathrm{SnO}_{2}$ layer at a great concentration of $\mathrm{SnCl}_{2}$ solution. This figure is related to the SEM photo of sample of 2.7 in that the lightness and reflectance are small, because the thickness of $\mathrm{SnO}_{2}$ layer is so high.

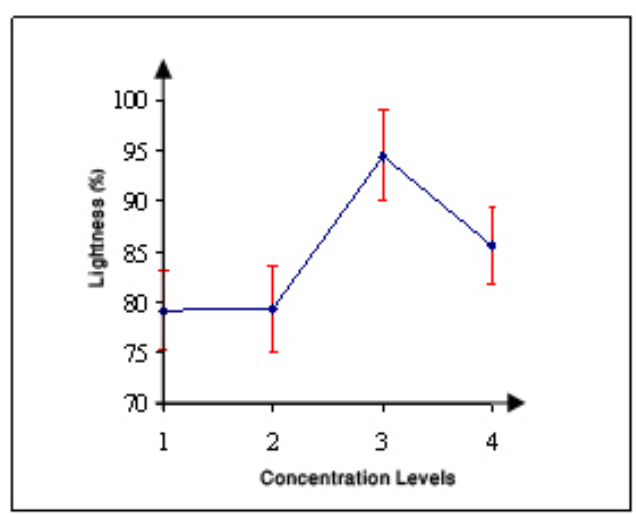

(a)

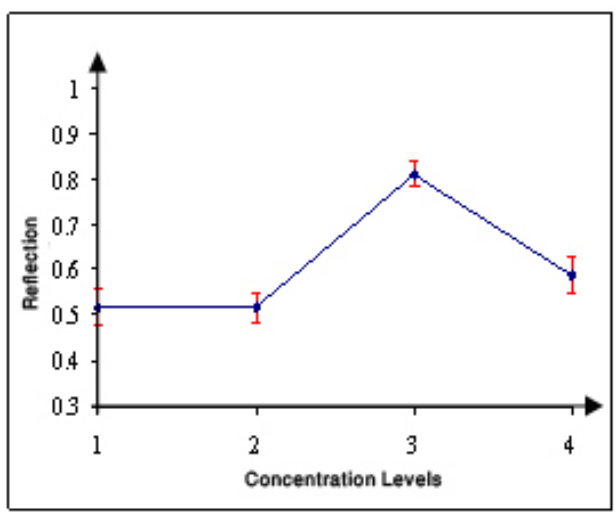

(b)

Fig. 2.8. Effect of concentration parameter on the a) lightness and b) reflection, at different levels 


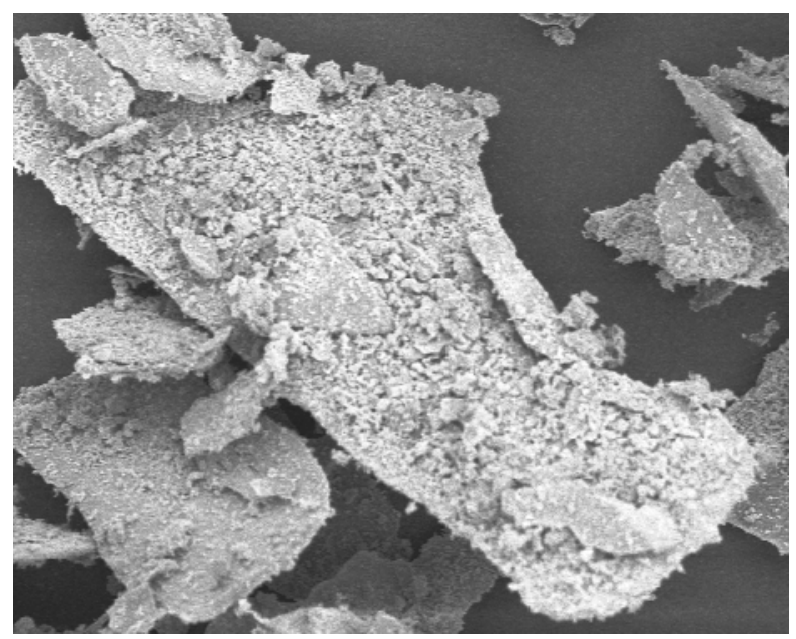

Fig. 2.9. SEM image of pigment synthesized at great concentration

\subsubsection{Reaction time}

By observing brightness and reflectance versus reaction time based on the Taguchi method, it can be observed that the maximum of lightness and reflectance are related to reaction time of about level 2 (Fig. 2.10).

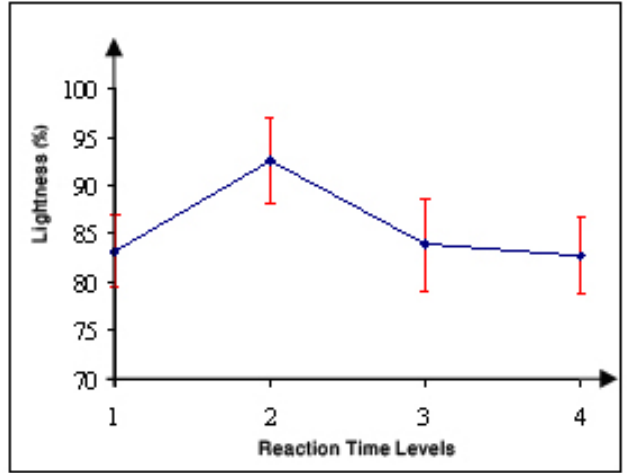

(a)

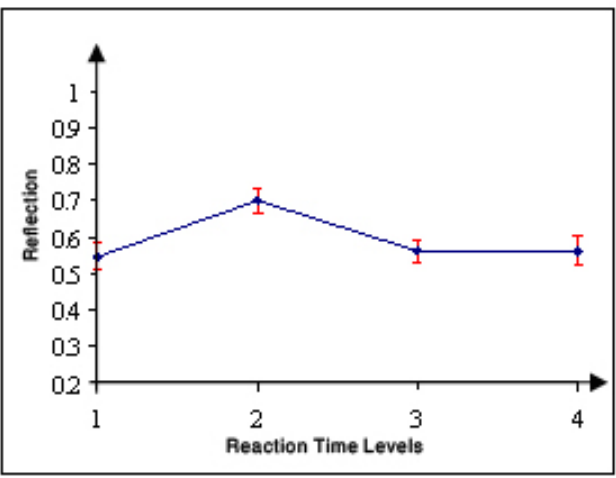

(b)

Fig. 2.10. Effect of time parameter on the a) lightness and b) reflection, at different levels

As SEM analysis show in figures 2.11-a and 2.11-b, when reaction time is low a few coating of $\mathrm{SnO}_{2}$ are formed on the mica flakes, thus lightness and reflectance are decreased (figure 2.11-a). While increase of reaction time, until level of 2, a uniform $\mathrm{SnO}_{2}$ coating is formed on the mica flakes and thus, lightness and reflectance increase as shown in figure 2.13-b. However, increasing time more than level 2 causes decreasing of lightness and reflectance, because the $\mathrm{SnO}_{2}$ coatings formed on the mica flakes are separated gradually. 


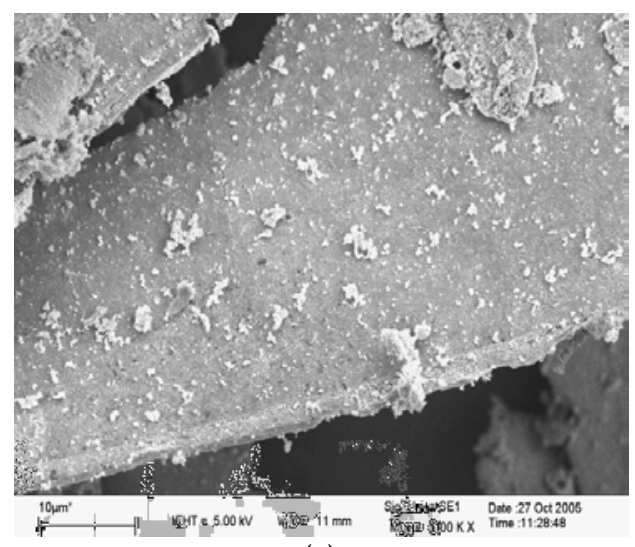

(a)

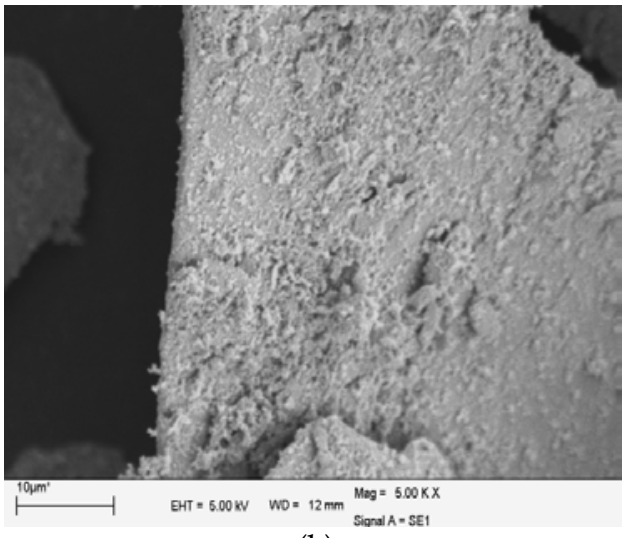

(b)

Fig. 2.11. SEM images of pigments synthesized at different levels of reaction time

\subsubsection{Stirring rate}

By observing brightness and reflectance versus stirring time based on (Figures 2.12-a and 2.12-b) Taguchi method, it can be seen that the maximum of lightness and reflectance are related to a stirring rate of about level 2 .

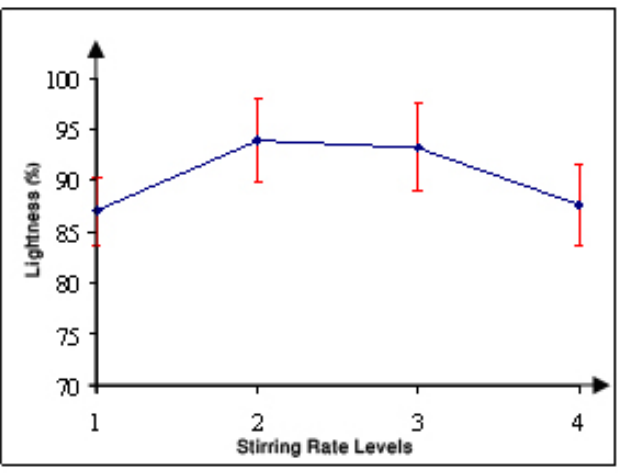

(a)

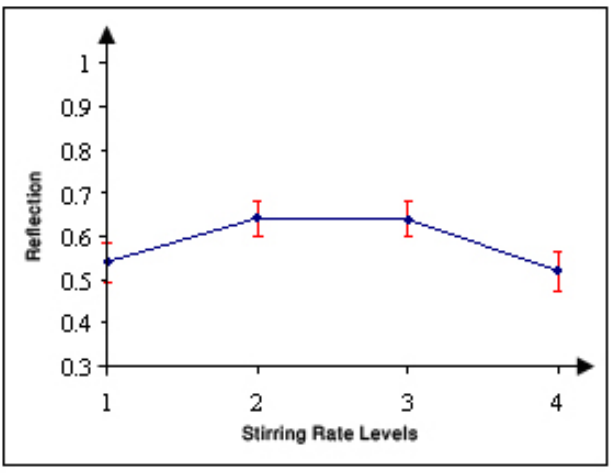

(b)

Fig. 2.12. Effect of stirring rate parameter $\mathrm{R}$ on the a) lightness and $\mathrm{b}$ ) reflection at different levels

The stirring rate affects the densification of the membrane layer directly. If the stirring rate is too low, the reaction solution can not form sufficient turbulence [2.17], then the microscopic mixture is uneven, and the generated crystal particles of $\mathrm{SnO}_{2}$ are of various sizes. On the other hand, if the stirring rate is too high, it will affect the rate of growing of the crystal nucleus, with the result that some tiny colloidal micro-particles enter the solution through the filter paper rather than depositing on the surface of mica flakes, which will cause the light to scatter. Therefore, the stirring rate in this reaction should be of level 2. 


\subsubsection{Surfactant effect}

Figure 2.13 shows the SEM images of optimized sample with surfactant and without it. As figure 2.13-a shows in the sample containing surfactant, $\mathrm{SnO}_{2}$ particles coat mica flakes uniformly without any agglomeration. In addition, these particles agglomerate on mica flakes only and are not formed freely among mica flakes, but in the sample without surfactant, $\mathrm{SnO}_{2}$ particles formed irregularly and are agglomerated on mica flakes and also freely among them (Figure 2.13-b).

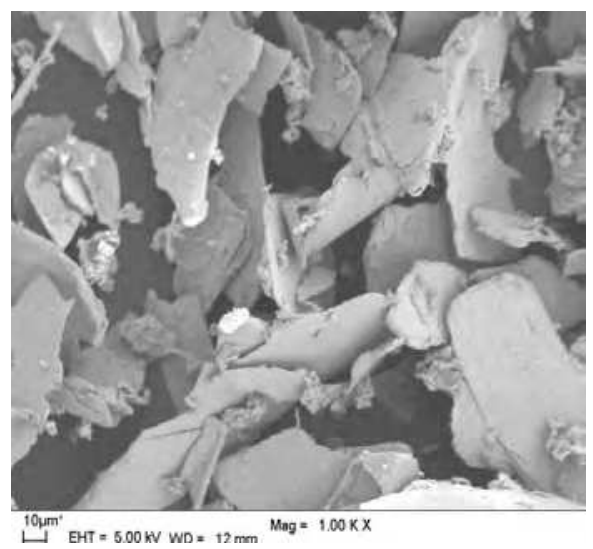

(a)

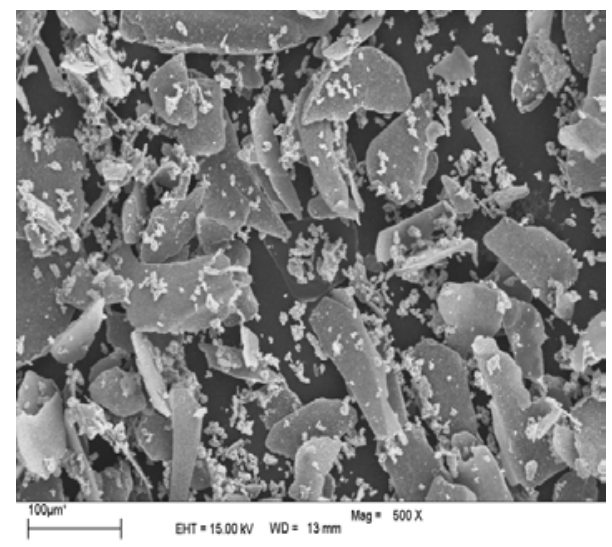

(b)

Fig. 2.13. SEM images of coated mica flakes in optimized sample a) with surfactant in magnification of $1 \mathrm{KX}$ and b) without surfactant in magnification of $500 \mathrm{X}$

Surfactant molecules are able to surround a small volume of suspension including seed and due to repulsive forces between electrical charged boundaries of mica and $\mathrm{SnOH}$ particles, prevent the over sticking of particles and growth of agglomerates [2.13, 2.18, 2.19]. In addition the mica boundary and hydrated metal oxide formed by hydrolysis is activated with increasing amount of surfactant making for a smooth surface and stable adsorption [2.20].

\subsubsection{Optimized sample}

After performing experiments designed by Taguchi method and analysing results with Winrobust software the optimized sample was provided using the following condition: $\mathrm{pH}=2.5, \mathrm{~T}=65^{\circ} \mathrm{C}, \mathrm{C}=40 \mathrm{~g} /$ lit, $\mathrm{t}=7 \mathrm{~h}, \mathrm{R}=200$ r.p.m .

The XRD pattern of this sample shows the hydroxide phase before calcination and Casiterite $\mathrm{SnO}_{2}$ phase after that.

According to SEM results, $\mathrm{SnO}_{2}$ particles are coated on mica flakes almost regularly and uniformly (figure 2.13-a). According to the laser beam diffraction technique the mean particle size of pigments is about 65 micron. The density of this pigment is $3.3 \mathrm{~g} / \mathrm{cm}^{3}$ and the lightness and reflective percent are $97 \%$ and $89 \%$ respectively in which case these amounts of $\mathrm{l}^{*}$ and $\mathrm{R}$ are equal to the Winborust software results. Consequently choosing to use the Taguchi method and $\mathrm{L}_{16}$ algorithm is correct for this work. 
Table 2.5 shows the results of Goniospectrophotometery of the optimized sample. Figure 2.14 shows the amount of optimized sample reflection from different angle views.

\begin{tabular}{ccccc}
\hline \multirow{2}{*}{$\begin{array}{c}\text { Colorimetery } \\
\text { parameters }\end{array}$} & $20^{\circ}$ & $45^{\circ}$ & $75^{\circ}$ & $110^{\circ}$ \\
\cline { 2 - 5 } & 0.81 & 0.74 & 0.73 & 0.67 \\
\hline $\mathrm{a}^{*}$ & 13.04 & 14.20 & 14.34 & 13.78 \\
\hline $\mathrm{b}^{*}$ & 96.76 & 87.57 & 87.03 & 86.99 \\
\hline $\mathrm{l}^{*}$ & 0.89 & 0.64 & 0.56 & 0.55 \\
\hline $\mathrm{R}_{570 \mathrm{~nm}}$ & & \multicolumn{4}{c}{ Angle view } \\
\hline
\end{tabular}

Table 2.5. R results of goniospectrophotometery of optimized sample

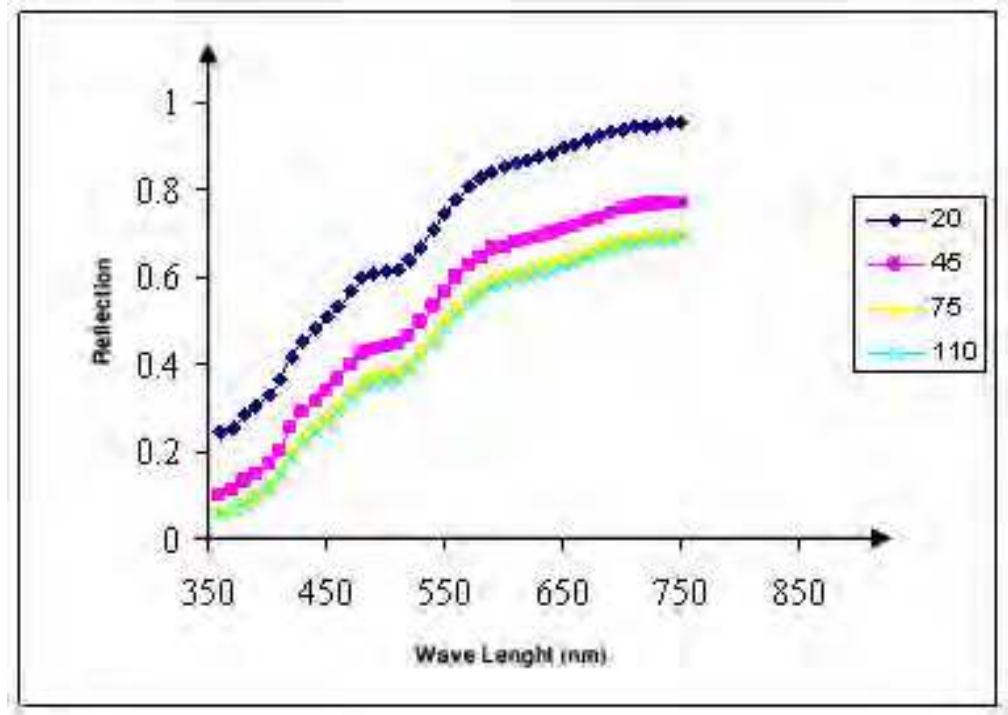

Fig. 2.14. Amount of optimized sample reflection from different angle views

According to table 2.5 and figure 2.14 parameters $\mathrm{l}^{*}$ and $\mathrm{R}$ in the different angle views have different values, and also these values are higher in smaller angle views. Therefore the optimized sample has lightness and reflection [2.21, 2.22]. In addition since the maximum value of reflection is in the range of yellow light wavelength $(570-600 \mathrm{~nm})$, the pigment is yellow. So it is possible to say that the optimized pigment is gold pearlescent pigment.

Figure 2.15 shows the microscopic image of the optimized sample. As can be seen from Fig. 2.14 and Fig. 2.15, most of mica flakes coated with $\mathrm{SnO}_{2}$ have a golden colour. However, in this sample, flakes with other colors can be seen as well, which might be due to different thickness of coating on the mica flakes. 


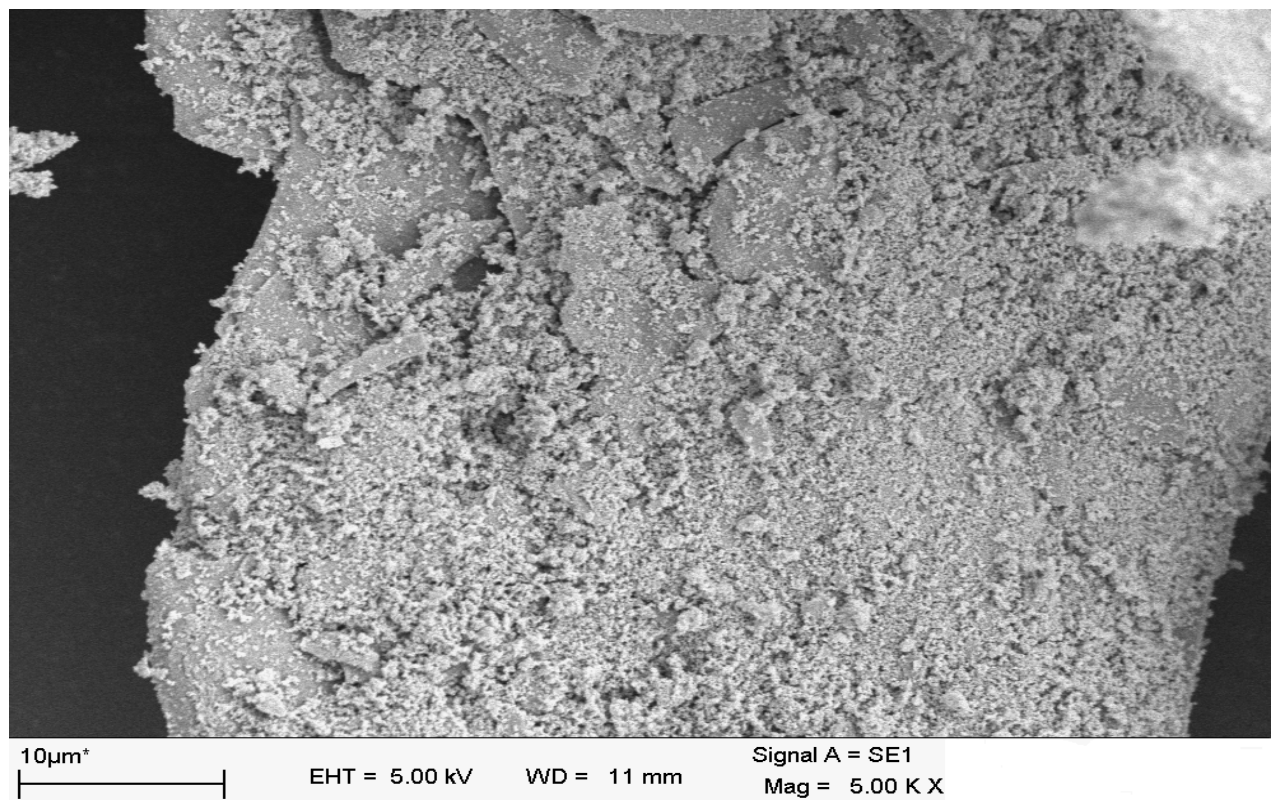

(a)

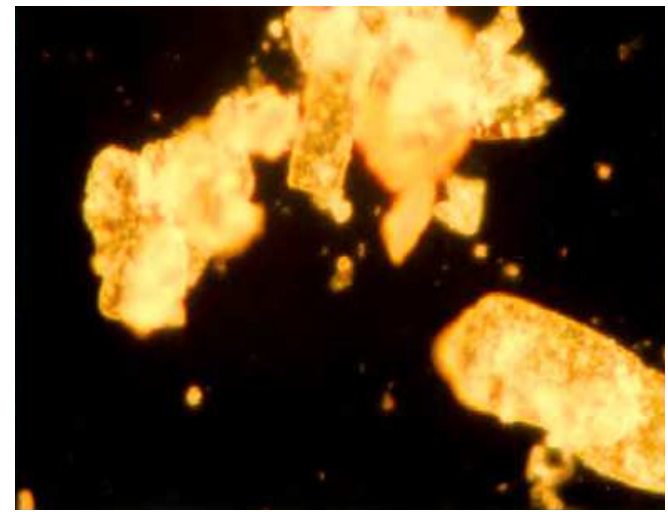

(b)

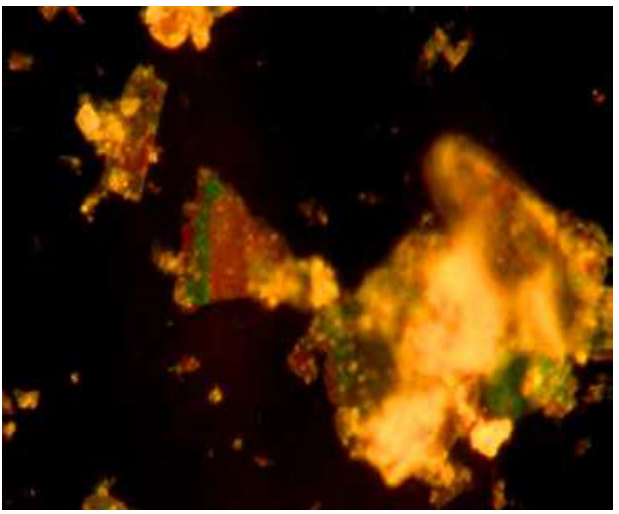

(c)

Fig. 2.15. Microscopic image of optimized sample, (a) SEM, (b) and (c) light microscopy 


\subsection{Chapter conclusions}

1. The results obtained in this research according to the Taguchi method, provide optimum values for $\mathrm{pH}$, temperature, concentration of $\mathrm{SnCl}_{2}$ solution, time and stirring velocity of $2.5,65^{\circ} \mathrm{C}, 40 \mathrm{~g} / \mathrm{lit}, 7 \mathrm{~h}$ and $200 \mathrm{rpm}$ respectively.

2. According to SEM investigation, a relatively good and homogenously flat coating is formed on the mica platelet at the optimum conditions.

3. The effects of using surfactant are: formation of a homogenous thickness of coating, specifically on the flakes surfaces and absence of intra particles agglomerations of $\mathrm{SnO}_{2}$. This is not the case without using the surfactant.

4. XRD analysis of the optimum sample before and after calcination show the amorphous and crystalline phase of $\mathrm{SnO}_{2}$ and Casiterite respectively.

5. Colourimetry measurements show a bright golden appearance of the optimum pigment.

6. Light microscopic observation of the coated flakes using a polarized filter shows that the majority of the flakes have the golden colour, implying the final interference pigment colour of the optimum synthesized pigment is a golden one [2.23].

\section{Acknowledgement}

Thanks are due to Mrs M. Esfidari who helped for preparation of second part of this chapter.

\section{References}

\subsection{Part one references}

[1.1] Glausch, R., Kieser, M., Maisch, R., Pfaff, G., Weitzel, J., Special Effect Pigments, Vincentz Verlag, Hannover, 1998.

[1.2] Pfaff, G., Franz, K.-D., Emmert, R., Nitta, K., Ullmann's Encyclopedia of Industrial Chemistry: Pigments, Inorganic, see Section $4.3,6$ th edn. (electronic release), VCH Verlagsgesellschaft, Weinheim, 1998.

[1.3] Pfaff, G., Chem. Unserer Zeit 31, (1997), p. 6.

[1.4] Pfaff, G., High Performance Pigments (Ed.: Smith, H. M., Wiley-VCH, Weinheim, 2002, p. 77.

[1.5] Ostertag, W., Nachr. Chem. Tech. Lab. 42 (1994), p. 849.

[1.6] Bäumer, W., Farbe + Lack 79 (1973), p. 747.

[1.7] Greenstein, L. M., Pigment Handbook, Part 1, Wiley, New York, 1988, p. 829.

[1.8] Schmidt, C., Friz, M., Kontakte (Darmstadt) 2 (1992), p. 15.

[1.9] Pfaff, G., Reynders, P., Chem. Rev. 99 (1999), p. 1963.

[1.10] Hofmeister, F., Eur. Coat. J. 3 (1990), p. 80.

[1.11] Hofmeister, F., Pieper, H., Farbe + Lack, 95 (1989), p. 557.

[1.12] Buxbaum, G. and Pfaff, G., Industrial Inorganic Pigments, Third, Completely Revised, _c WILEY-VCH Verlag GmbH \& Co KGaA, Weinheim, 2005.

\subsection{Part two references}

[2.1] Buxbaum, G. and Pfaff, G., Industrial Inorganic Pigments, Third, Completely Revised, _c WILEY-VCH Verlag GmbH \& Co KGaA, Weinheim, 2005. 
[2.2] S. Hanchisu, “Nacreou Pigments”, Prog. Org. Coat. 3:191-220 (1975).

[2.3] K.Othmer, "Encyclopedia of Chemical Technology", 3rd ed., 17, J.Wiley \& sons, NewYork, 1978-1984, PP. 78-838.

[2.4] G. Taguchi and S. Konishi, Taguchi methods, orthogonal arrays and linear graphs, tools for quality engineering, American Supplier Institute, Dearborn, MI (1987) p. 35-38.

[2.5] G. Taguchi, Taguchi on robust technology development methods, ASME Press, New York, NY (1993) p. 1-40.

[2.6] Phillip J. Ross, Taguchi Technique for quality engineering, McGraw-Hill, New York (1988).

[2.7] K. Roy Ranjit, A Primer on Taguchi method, Van Nostrad Rainhold, New York (1990).

[2.8] J. Paulo Davim, An experimental study of tribological behaviour of the brass/steel pair, J Mater Process Technol 100 (2000), p273-279.

[2.9] J. Paulo Davim, Design optimization of cutting parameters for turning metal matrix composites based on the orthogonal arrays, J Mater Process Technol 132 (2003), p. 340-344.

[2.10] Genechi Taguchi, “System of Experimental Design” Vol. 1, 1987, KRAUS International Publication.

[2.11] Yeow Nam Ng, Don Black, Khanh Luu, “Taguchi Methods”, 1995, Curtin University Handout Notes for Computer Aided Engineering.

[2.12] T. Junru, Sh. Lazhen, F. Xian song, H. Wenxiang, “Preparation of Nanometer - Sized (1-x) $\mathrm{SnO}_{2}$. $\mathrm{xsb}_{2} \mathrm{O}_{3}$ Conductive Pigment Powders and the Hydrolysis Behavior of Urea", Dyes and pigments 61 (2004) 31-38.

[2.13] J. P. Jolivet, "Metal Oxide Chemistry and Synthesis", John Wiley \& Sons, (2002).

[2.14] M. Yamamoto, A. Ando, "Pearlescent Pigment, and Paint Composition, Cosmetic Material, Ink and Plastics Blended with the New Pearlescent Pigment", U.S. Patent 5741355 (1998).

[2.15] H.R.Castro, B.S.Murad, D.Gouvea, "Influence of the Acid-Basic Character of Oxide Surfaces in Dispersants Effectiveness" Ceramics International 30 (2004) 22152221.

[2.16] Miller HA. Optical property of pearl pigment GFR. Farbe lack 1987; 12:93.

[2.17] Xiong Y, Zhou X, Hu L. Study on the process of the ultrafine a-FeOOH synthesis by dripping method. Journal of East china university of science and technology 1996; 22(5): 541-7.

[2.18] K. Matsui, M. Ohgai, "Formation Mechanism of Hydrous Zirconia Particle Produced by Hydrolysis of $\mathrm{ZrCL}_{2}$ Solution, Kinetics Study for Nucleation and Crystal Growth Processes of Primary Particle", J. Am. Ceram. Soc. 84: 2203-2313 (2001).

[2.19] M.R. Porten, "Hand book of Surfactan", Chapter 4, Chapter 8, Hall (1994).

[2.20] K.Chang, etal, "A Method for Preparing a Pearlescency Pigment", U.S. Patent. APPL. 20040096579 (2004).

[2.21] H.M.Smith, "High Performance Pigment", Chapter 7, Wiley- VCH, Weinheim, Germany, (2002).

[2.22] L.M. Greenteain, "Pigment Handbook", Vol. 1, Chapter III-D-d-2, John Wiley \& Sons NewYork (1998). 
[2.23] M. Esfidari, "Preparation of Pearlescent Pigments for Low Temperature Glazes", MSc Thesis, Ceramic Department, Iran University Of Science and Technology, Tehran, Iran 2005. 


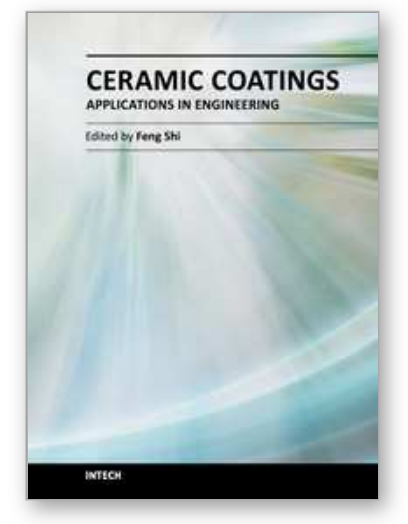

\author{
Ceramic Coatings - Applications in Engineering \\ Edited by Prof. Feng Shi
}

ISBN 978-953-51-0083-6

Hard cover, 286 pages

Publisher InTech

Published online 24, February, 2012

Published in print edition February, 2012

The main target of this book is to state the latest advancement in ceramic coatings technology in various industrial fields. The book includes topics related to the applications of ceramic coating covers in enginnering, including fabrication route (electrophoretic deposition and physical deposition) and applications in turbine parts, internal combustion engine, pigment, foundry, etc.

\title{
How to reference
}

In order to correctly reference this scholarly work, feel free to copy and paste the following:

A.R. Mirhabibi (2012). Ceramic Coatings for Pigments, Ceramic Coatings - Applications in Engineering, Prof. Feng Shi (Ed.), ISBN: 978-953-51-0083-6, InTech, Available from: http://www.intechopen.com/books/ceramiccoatings-applications-in-engineering/ceramic-coatings-for-pigments

\section{INTECH}

open science | open minds

\section{InTech Europe}

University Campus STeP Ri

Slavka Krautzeka 83/A

51000 Rijeka, Croatia

Phone: +385 (51) 770447

Fax: +385 (51) 686166

www.intechopen.com

\section{InTech China}

Unit 405, Office Block, Hotel Equatorial Shanghai

No.65, Yan An Road (West), Shanghai, 200040, China

中国上海市延安西路65号上海国际贵都大饭店办公楼405单元

Phone: +86-21-62489820

Fax: +86-21-62489821 
(C) 2012 The Author(s). Licensee IntechOpen. This is an open access article distributed under the terms of the Creative Commons Attribution 3.0 License, which permits unrestricted use, distribution, and reproduction in any medium, provided the original work is properly cited. 